\title{
Fluxos de capitais, fragilidade externa e regimes cambiais - uma revisão teórica
}

\author{
LUCIANO FERREIRA GABRIEL \\ JOSÉ LUÍS DA COSTA OREIRO*
}

Capital Flows, External Fragility and Currency Regimes: A Theoretical Review. The major integration and deregulation of the international financial markets increased the degree of interdependence and risk of incompatibility between the financial and monetary policy adopted by different countries. The consequences of these facts are the financial instability and the currency crisis. In this article we develop arguments advocating that independent of the currency regime adopted the national policy makers should take into account, between other factors, the major capital mobility and the integrations of markets. One of the corollaries of our analyses is that countries should pursue policies that reduces the degree of short-term capital volatile by the adoption of capital controls or though measures of prudential supervision.

Keywords: currency regime, capital flows, self-fulfilling prophecies, sunspots, herding behavior.

JEL Classification: E44; F31; F32; F36.

\section{INTRODUÇÃO}

O aumento dos fluxos internacionais de capitais e a tendência à integração dos mercados criaram novos elementos na condução das políticas econômicas nacionais. A expansão das operações financeiras internacionais coloca limites à condução destas políticas, em especial no campo monetário-financeiro. ${ }^{1}$

\footnotetext{
* Mestre em Desenvolvimento Econômico pela Universidade Federal do Paraná (UFPR) e Pesquisador do Boletim Economia \& Tecnologia do CEPEC-UFPR, e-mail: lucianofg@gmail.com; Doutor em Economia pelo IE-UFRJ, Professor Adjunto do Departamento de Economia da Universidade Federal do Paraná (UFPR), Diretor do Centro de Pesquisas Econômicas (CEPEC-UFPR) e Pesquisador do CNPq, e-mail: joreiro@ufpr.br. Submetido: Abril 2006; Aceito: Junho 2006.
}

${ }^{1}$ Para uma melhor discussão deste aspecto veja Batista Jr. (1998). 
Kregel (2004) constata que, a partir da década passada, os mercados financeiros se tornaram mais integrados no âmbito global. Contribuiu para esse fenômeno, dentre outros fatores, o processo de liberalização das contas de capitais nos primeiros anos da década de 70 com o abandono de regras do sistema de Bretton Woods, sendo tal processo mais acentuado nos países desenvolvidos, em um primeiro momento. Nos países em desenvolvimento esse processo adquire uma forma mais bem definida a partir do final da década de 80 e se intensifica nos anos 90. No Brasil, em especial, Soihet (2002) demonstra que a abertura da conta de capitais se apresentou como uma tendência geral nos anos $90 .^{2}$

A maior integração e desregulamentação dos mercados financeiros internacionais aumentaram o grau de interdependência e também o risco de incompatibilidade entre as políticas monetárias e financeiras adotadas por diferentes países. Isso ocasionou uma crescente instabilidade financeira, mais evidente nos últimos tempos em forma de crises cambiais, que afetou sobremaneira a condução das políticas nacionais. ${ }^{3}$

No que se refere, em especial, às políticas monetária e financeira, essas mudanças no quadro financeiro internacional têm mostrado cada vez mais que há uma dificuldade crescente, por parte dos bancos centrais, de sustentarem determinados tipos de regimes cambiais, principalmente para aqueles regimes que se caracterizam por ancoragem cambial, isto é, aqueles que estabelecem sistemas ajustáveis de câmbio fixo, prefixações, bandas cambiais, dentre outros. ${ }^{4}$ Particularmente na última década, tivemos várias ocorrências de graves crises cambiais e financeiras nas economias em desenvolvimento, como as crises do México (1994), Ásia (1997), Rússia (1998), Brasil (1999 e 2002), Turquia (2001) e Argentina (2001), cujas repercussões se prolongaram para as demais economias em desenvolvimento por meio do efeito contágio. Nem mesmo com a adoção do câmbio flutuante em 1999, o Brasil conseguiu se ver livre de certa instabilidade cam-

\footnotetext{
${ }^{2}$ Para uma análise da mudança do marco regulatório pertinente a contas de capitais veja também Franco e Neto (2004).

${ }^{3}$ Além da literatura a respeito das crises cambiais, surgiu uma ampla literatura de modelos teóricos que sublinham um conjunto de canais através dos quais a liberalização da conta de capitais levaria a uma melhor alocação de recursos, estimulando o crescimento econômico através do aumento da poupança doméstica (Fisher, 1998), redução dos custos do capital (Prasad, Rogoff et al., 2003), transferência de tecnologia (Agénor, 2003), desenvolvimento do sistema financeiro doméstico (Einchengreen et al., 1998) e disciplina macroeconômica (Prasad, Rogoff et al., op. cit). No entanto, a partir de várias análises empíricas com diferentes metodologias para os indicadores de liberalização da conta de capitais, como o estudo pioneiro de Quinn (1997), de Rodrik (1998) e Edison, Levine, Ricci e Sloek (2002), Edison, Klein, Ricci e Sloek (2002), observa-se que não existe um consenso de que a liberalização da conta de capitais tenha efeitos positivos sobre o crescimento econômico dos países. Como foge do escopo do presente trabalho uma análise pormenorizada desta literatura, sugerimos os trabalhos de Ono et al., (2006) para uma análise da experiência brasileira e de Damasceno (2005) para alguns países selecionados da América Latina.

${ }^{4}$ Para uma análise das características dos diferentes regimes cambiais veja Garofalo Filho (2000).
} 
bial que culminou com o efeito sudden stop (parada súbita) do influxo de capitais em 2002, ocorrendo uma depreciação de quase $50 \%$ do câmbio em um curto período de tempo.

Essas crises monetárias, segundo Krugman (2001), vêm sendo uma característica recorrente da economia internacional desde que as moedas de ouro e prata foram substituídas por papel-moeda; as crises monetárias desempenharam um papel preponderante na turbulência da época entre as duas guerras mundiais, no colapso de Bretton Woods e nos estágios iniciais da crise de endividamento da América Latina nos anos 80.

Dentro do contexto desta discussão o nosso objetivo neste artigo é de mostrar que: a) a maior integração financeira gera uma perda de autonomia da política econômica independente do regime cambial adotado e b) não há nenhum tipo de regime cambial livre de ataques especulativos, ou seja, tanto nos regimes de câmbio fixo quanto flutuante (ou mesmo nos regimes intermediários) há a possibilidade de ocorrência de crises monetárias e/ou financeiras. Nesse sentido, se aceitarmos a hipótese de que um dos fatores centrais que pressionam qualquer regime cambial tem origem no grande e instável fluxo de capitais, então devemse buscar medidas que reduzam a magnitude e volatilidade dos mesmos.

Para cumprirmos estes objetivos dividimos o presente artigo em 4 seções. $\mathrm{Na}$ seção 1 discutimos a relação entre a perda de autonomia de políticas econômicas nacionais, os fluxos de capitais e os regimes cambiais. Na seção 2 discutimos a possibilidade de ocorrência de crises cambiais baseadas em corridas bancárias a là Diamond e Dybvig (1983), self-fulfilling prophecies (profecias auto-realizáveis), herding behaviour (comportamento manada) e a ação de sunspots no desencadeamento de ataques especulativos. Nas seções 3 e 4 apresentamos formalmente os modelos de Rodrik e Velasco (1999) e Licha (2000), respectivamente, os quais não só mostram a possibilidade de ocorrência de crises cambiais sob diversos regimes de câmbio, como ainda nos darão subsídios teóricos importantes para nossas considerações finais na seção 5 .

\section{A PERDA DE AUTONOMIA DA POLÍTICA ECONÔMICA, OS FLUXOS DE CAPITAIS E REGIMES CAMBIAIS}

Depois da crise asiática de 1997, alguns pesquisadores como Frankel, Schmukler e Servén (2000) chegaram à conclusão de que os países emergentes deveriam optar entre um regime de câmbio totalmente fixo ou, no outro extremo, totalmente flutuante. No primeiro caso, o câmbio fixo deveria ser empregado através de um regime de currency board ou de uma união monetária com moedas fortes, como o dólar ou o euro. Estes autores acreditam que regimes cambiais intermediários não são mais factíveis atualmente. 
Segundo Grenville (2000), a racionalidade de idéias como as dos autores supracitados é diferente dos argumentos dos manuais de macroeconomia tradicional sobre a escolha de regimes cambiais. Esses argumentos têm como base o modelo Mundell-Fleming, em que são estabelecidas as condições nas quais é possível avaliar os resultados das políticas monetária e fiscal sob regime de câmbio fixo ou flexível, supondo-se mobilidade plena, parcial ou zero de capitais. ${ }^{5}$

O novo argumento desenvolvido por Frankel, Schmukler e Servén (2000) é uma resposta à volatilidade dos fluxos de capitais e à ameaça de ataques especulativos. Pelo menos a priori, os regimes de câmbio fortemente fixos e de flutuações livres seriam imunes a estes ataques. No que diz respeito a um regime fortemente fixo, a ênfase seria dada à credibilidade e à irrevogabilidade deste regime. Já no regime puramente livre, o mesmo teria a capacidade de resistir a um ataque ou a uma grande volatilidade dos fluxos de capitais sem o colapso do regime cambial.

Os argumentos de Frankel, Schmukler e Servén (2000) e os colocados tendo-se por base o modelo Mundell-Fleming não levam em conta uma série de características de economias emergentes como: i) moedas não conversíveis internacionalmente (como o dólar ou o euro); ii) grande volatilidade nos fluxos de capitais externos e iii) recorrência e persistência de déficits em transações correntes. A operação de um regime de câmbio flutuante sob tais circunstâncias faz com que a taxa de câmbio nominal esteja associada a uma grande volatilidade, o que, segundo Grenville (2000): a) inibe os investimentos em capital fixo ao aumentar o risco cambial das operações de importação de bens de capital; b) obriga o Banco Central a operar com taxas de juros nominais e reais elevadas para impedir o re-

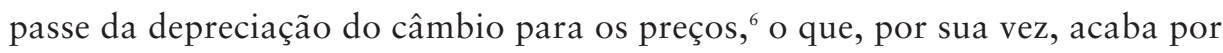
desestimular o crescimento econômico ao impedir que a demanda agregada acom-

\footnotetext{
${ }^{5} \mathrm{O}$ ponto central deste modelo é determinar qual o regime cambial que um país deve adotar para que sua política econômica doméstica (fiscal e monetária) seja eficaz, influenciando o nível de produção e de emprego. Sob a hipótese de livre mobilidade de capitais, o regime de câmbio fixo possui a vantagem de reduzir os custos de transação e o risco cambial. Nestas circunstâncias, a política fiscal seria apenas parcialmente eficaz, uma vez que o controle do déficit público é fundamental para a manutenção do regime de câmbio fixo. Contudo, há a desvantagem de implicar a perda de autonomia na condução da política monetária. No caso de um regime cambial flexível, a política monetária pode ser usada para a expansão dos níveis de renda e emprego, ainda que sujeita às dificuldades impostas pela volatilidade dos fluxos de capitais. Nesse sentido, uma análise com base no modelo de Mundell-Fleming sugere a adoção de um regime de câmbio flutuante, tendo-se em vista que seria o único regime compatível com algum grau de autonomia para a política monetária.As hipóteses do modelo Mundell-Fleming são as seguintes: (i) país pequeno; (ii) inexistência de uma defasagem temporal entre a ocorrência de um choque e a realização dos ajustamentos; (iii) capacidade ociosa em conformidade com a tradição keynesiana; (iv) condição de Marshall-Lerner satisfeita — isto é, uma desvalorização cambial promove um aumento das exportações líquidas e (v) as expectativas dos agentes econômicos são estáveis. Para maiores detalhes a respeito do modelo veja Mundell (1963) e Fleming (1962).

${ }^{6}$ Esse fenômeno é chamado de pass-through inflacionário.
} 
panhe a expansão da capacidade produtiva, resultando em grande capacidade ociosa, o que acaba por gerar expectativas negativas em relação aos novos investimentos.

Figura 1: Trindade Impossível

Controle de Capitais

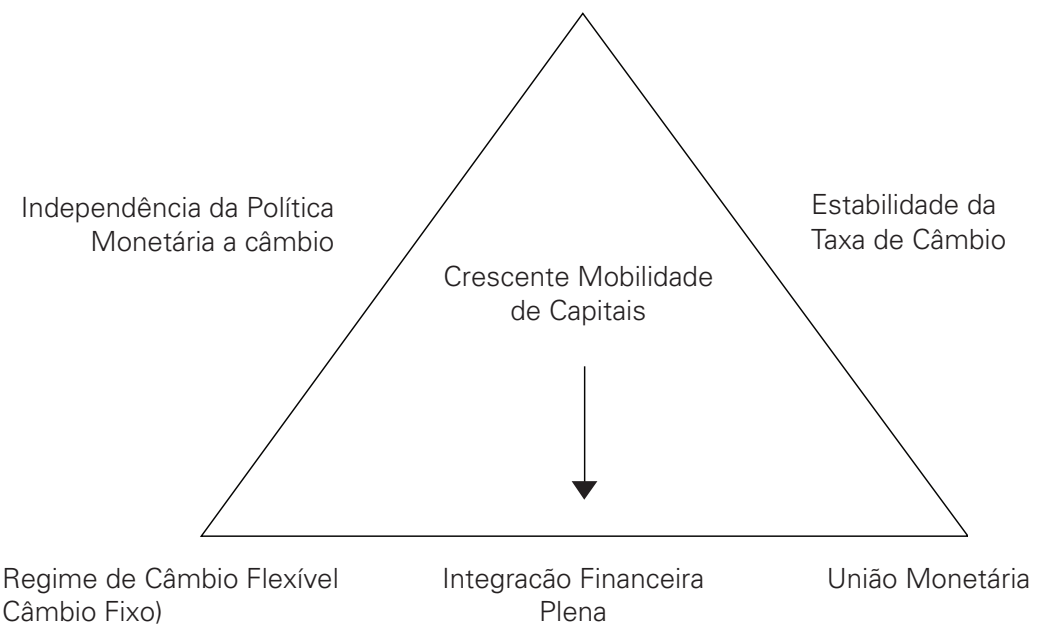

Fonte: FRANKEL (1999)

Frankel (1999) nos diz que a hipótese de que regimes cambiais intermediários não funcionem é uma derivação do princípio da "trindade impossível" (veja Figura 1), a qual tem tido bastante suporte empírico dado os inúmeros casos de colapsos de regimes cambiais intermediários. Esse princípio diz que um país tem que abrir mão de um dos três objetivos: estabilidade da taxa de câmbio (câmbio fixo), independência da política monetária e integração do mercado financeiro (o que implica maior mobilidade de capitais). Não é possível pôr em prática estes três objetivos ao mesmo tempo.

A Figura 1 é uma ilustração esquemática da "trindade impossível" de Frankel (1999). Nela vemos que somente as "soluções de canto" são factíveis, combinando no máximo dois objetivos. ${ }^{7}$

$\mathrm{Na}$ década de 90 algumas economias que estavam sob um regime de infla-

\footnotetext{
${ }^{7}$ Cada lado da Figura 1 tem um atrativo: independência monetária, estabilidade da taxa de câmbio e integração financeira plena. Um país pode ter ao mesmo tempo apenas dois desses atributos, ou seja, para se ter estabilidade de câmbio e independência monetária, devemos ter certo grau de controle de capitais, caso o objetivo seja integração financeira plena e estabilidade da taxa de câmbio devemos ter uma união monetária e financeira (o que implica a adoção de câmbio fixo). Agora, se quisermos uma integração financeira plena (o que implica livre mobilidade de capitais) e independência da política monetária, devemos ter um regime de câmbio flutuante.
} 
ção alta, por vezes crônica e com fortes componentes de indexação de preços, demonstraram um nítido movimento de adoção de regimes cambiais mais fixos como instrumento da política de combate à inflação. Afinal, a recuperação do padrão monetário doméstico implica algum vínculo com outra moeda, seja este vínculo mais brando, seja mais rígido, como a própria substituição da moeda doméstica por alguma moeda forte.

Quando há certa persistência temporal na adoção de regimes cambiais mais fixos, observam-se problemas associados aos desequilíbrios macroeconômicos daí advindos, o que equivaleria a um problema de inconsistência temporal após o êxito inicial da adoção deste regime cambial. ${ }^{8}$ Um movimento na direção à adoção de taxas de câmbio mais flexíveis começa a se apresentar, onde regimes de câmbio do tipo fixo, ou mais rígido, como o currency board, são provavelmente de reversibilidade mais danosa do que regimes mais flexíveis (como o crawling peg). A transição de regimes de câmbio mais fixos para mais flexíveis pode ocorrer sob condições de crise cambial, ou seja, de modo não administrado pela autoridade monetária. Neste particular, nossos exemplos são vastos se analisarmos os últimos 15 anos.

Obstfeld e Rogoff (1995) destacam que regimes com câmbio fixo, em geral, não duram mais do que 5 anos. O Banco da Inglaterra teve prejuízos de US\$ 5 bilhões em poucas horas na tentativa de impedir o colapso de sua moeda em setembro de 1992. Muitos outros Bancos Centrais europeus sofreram problemas similares em 1992-93. Na verdade, naquela época, o Sistema Monetário Europeu (SME) foi forçado a ampliar sua banda cambial em $30 \%$ ( $\pm 15 \%$ em torno de uma taxa central), um sistema mal distinguível do flutuante. ${ }^{9}$

Em relação ao câmbio flutuante, as visões de como a livre flutuação funcionaria na prática tem mudado nas últimas décadas à luz da experiência internacional. Os primeiros protagonistas em defesa de tal regime eram confiantes de que taxas de câmbio flutuantes seriam estáveis e refletiriam os fundamentos de

\footnotetext{
${ }^{8}$ A taxa de câmbio pode ser usada em um primeiro momento nos programas de estabilização como uma âncora nominal, sincronizando expectativas e interrompendo mecanismos que tendem a perpetuar a inflação (como indexação formal). Contudo, o uso continuado desta estratégia pode trazer sérias distorções, como prejudicar as exportações domésticas. Para uma maior discussão a este respeito veja Cardoso e Helwege (1999).

${ }^{9}$ Fatos similares, só que com conseqüências mais graves, ocorreram nos países emergentes na tentativa de manterem seus regimes cambiais fixos. No caso do México em 1994, por exemplo, foram gastos US\$ 25 bilhões em reservas e foram realizados empréstimos da mesma ordem para defender o peso (o qual estava fixado ao dólar). Contudo, o país sofreu grandes perdas e o peso entrou em colapso no final daquele ano. Esses eventos de crises cambiais não são sem precedentes, mas seu escopo e magnitude têm chamado a atenção sobre a viabilidade da manutenção de regimes cambiais fixos entre nações soberanas em um mundo com um mercado global de capitais altamente desenvolvidos, o qual magnifica qualquer "fraqueza" de um país comprometido com um regime cambial fixo e deixa pouca margem para manobras de política econômica das autoridades monetárias.
} 
uma determinada economia. Dois exemplos clássicos na literatura são os de Friedman (1953) e Johnson (1972).

Para Friedman (1953), regimes de câmbio flexível são a contrapartida internacional lógica da estrutura de políticas monetárias e fiscais para a estabilidade econômica que seriam as mais promissoras. Em sua defesa sobre regimes de câmbio flexível, Friedman (1953, p. 158) nos diz que:

"[...] a world in which exchange rates, while free to vary, are in fact highly stable. Instability of exchange rates is a symptom of instability in the underlying economic structure. Elimination of this symptom by administrative freezing of exchange rates cures none of the underlying difficulties and only makes adjustment to them more painful”.

Em outro ponto, resumindo suas idéias sobre regimes cambiais flexíveis, Friedman (1953) advoga que:

“[...] flexible exchange rates are means of combining interdependence among countries through trade with a maximum of internal monetary independence; they are a means of permitting each country to seek for monetary stability according to its neighbors or having their mistakes imposed on it. If all countries succeeded, the result would be a system of reasonably stable exchange rates [...]" (Friedman, 1953, p. 200).

Johnson (1972) segue de perto as opiniões de Friedman (1953) a respeito de regimes cambiais flexíveis. Os argumentos deste autor em prol deste regime cambial no que se refere à autonomia das políticas monetárias e fiscais, bem como a estabilidade cambial podem ser resumidas fundamentalmente como se segue:

"The fundamental argument for flexible exchange rates is that they would allow countries autonomy with respect to their use of monetary, fiscal and other policy instruments, consistent with the maintenance of whatever degree of freedom in international transactions they chose to allow their citizens, by automatically ensuring the preservation of external equilibrium. Since, in the absence of balance-of-payments reasons for interfering in the international trade and payments, and given autonomy of domestic policy, there is an overwhelmingly strong case for the maximum possible freedom of international transactions to permit exploitation of the economies of international specialization and division of labor, the argument for flexible exchange rates can be put more strongly still: flexible exchange rates are essential to the preservation of national 
autonomy and independence consistent with efficient organization and development of the world economy" (Johnson, 1972, p. 199).

Os defensores do regime cambial flexível são confiantes de que a taxa de câmbio seria estável e refletiria os fundamentos macroeconômicos de uma determinada economia doméstica. Segundo Johnson (1972, p. 208) "[...] a freely flexible exchange rate would tend to remain constant so long as underlying economic conditions (including governmental policies) remained constant; random deviation from the equilibrium level would be limited by activities of private speculators".

As hipóteses de Friedman (1953) e Johnson (1972) sobre a especulação cambial podem ser justificadas como sendo atividades estabilizadoras, onde os agentes prevêem o futuro de forma perfeita ou, pelo menos, podem estabelecer previsões estatisticamente confiáveis sem erros persistentes. ${ }^{10}$

Ao contrário de Friedman (1953) e Johnson (1972), Hart e Kreps (1986) e Davidson (2004) advogam que essa percepção estabilizadora da atividade especulativa é equivocada, uma vez que, segundo Hart e Kreps (1986, p. 927), "speculators buy when the chances of price appreciation are high, selling when the chances are low. Speculative activity in an economy in which all agents are rational, have identical priors, and have access to identical information may destabilize prices, under any reasonable definition of destabilization". ${ }^{11}$

Para Davidson (2004), o futuro econômico é incerto (não-ergódico ${ }^{12}$ ), os agentes de hoje "sabem" que não podem prever acontecimentos futuros com segurança. Nesse sentido, em um mundo dominado pela incerteza, os agentes econômicos não podem confiar em dados de séries históricas para preverem preços futuros com perfeita segurança (isto é, na falta de instituições confiáveis que assegurem mercados spot organizados, não pode existir uma âncora confiável para preços de mercados futuros).

Em um mundo como o descrito acima, não apenas as atividades especulativas podem ser altamente desestabilizadoras em termos de preços de mercados futuros, como também a volatilidade desses preços futuros spot pode ter conseqüências reais custosas para a renda real agregada de uma determinada economia. Nas palavras de Kaldor (1960):

\footnotetext{
${ }^{10}$ Para Friedman (1953, p. 175), "people who argue that speculation is generally destabilizing seldom realize that this is largely equivalent to saying that speculators lose money, since speculation can be destabilizing in general only if speculators on the average sell when the currency is low in price and buy when it is high".

${ }^{11}$ Além disso, esses autores demonstram que somente sob fortes condições as atividades especulativas estabilizariam os preços, mesmo quando o próprio conceito de "estabilidade" é flexibilizado.

${ }^{12}$ A não-ergodicidade se refere ao fato de que os processos econômicos não são homogêneos e, sendo assim, os acontecimentos passados não são úteis para construir uma distribuição de probabilidade única, aditiva e totalmente confiável dos acontecimentos futuros. Para uma maior discussão a este respeito veja Dequech (1999).
} 
“[...] the traditional theory can also be criticized from another point of view. It ignored the effect of speculation on the general level of activity - or rather, it concentrated its attention on price-stability and assumed (implicitly perhaps, rather than explicitly) that speculation can be shown to exert a stabilizing influence upon price, it will ipso facto have a stabilizing influence on activity. This, however, will only be true under certain special assumptions regarding monetary management which are certainly not fulfilled in the real world. [...] Its stabilizing influence on price will be accompanied by a destabilizing influence on activity" (Kaldor, 1960, p. 19).

$\mathrm{Na}$ análise de Kaldor (1960) a especulação afeta o nível de atividade através da variação dos estoques especulativos de qualquer mercadoria ou ativo. A atividade especulativa com qualquer mercadoria ou ativo, por criar variações não compensadas no montante de estoques, é a responsável pela variação no nível de atividade do produto. ${ }^{13}$

No bojo dessa discussão, alguns autores, entre os quais se destaca James Tobin (1978), advogam que a relação entre a autonomia da política econômica e a escolha dos regimes cambiais a serem adotados por qualquer economia nacional está mais fortemente influenciada pela mobilidade internacional de capitais do que a escolha do regime cambial em si.

Para Tobin (1978), o grande problema posto pela mobilidade internacional de capitais de curto prazo é que a mesma reduz drasticamente a autonomia dos governos para adotarem políticas econômicas que sejam apropriadas com as especificidades de suas respectivas economias. ${ }^{14}$

Isto posto, a redução de autonomia na condução da política monetária não é condicionada pela adoção de nenhum regime cambial em especial, ou seja, ela não ocorre apenas no caso do regime de câmbio fixo como é defendido pela macroeconomia tradicional, mas ela também se verifica no regime de câmbio flutuante.

\footnotetext{
${ }^{13}$ Para uma maior análise dos efeitos desestabilizadores da atividade especulativa sobre os preços e sobre o nível de atividade veja Hart e Kreps (1986) e Kaldor (1960), respectivamente.

${ }^{14}$ Nas suas palavras: "[...] Debate on the regime evades and obscures the essential problem. That is the excessive international or better, inter-currency-mobility of private financial capital. The biggest thing that happened in the world monetary system since the 1950s was the establishment of the facto complete convertibility among major currencies, and the development of intermediaries and markets, notably Eurocurrency institutions, to facilitate conversions. Under either exchange rate regime the currency exchanges transmit disturbances originating in international financial markets. National economies and national governments are not capable of adjusting to massive movements of funds across the foreign exchanges, without real hardship and without significant sacrifice of the objectives of national economic policy with respect to employment, output, and inflation" (Tobin, 1978, pp. 153-4).
} 
Tobin (1978) explica esta perda de autonomia na definição de políticas monetárias a um conjunto de razões. A primeira delas diz respeito ao impacto do efeito de uma depreciação cambial sobre a balança comercial, a qual é perversa no curtíssimo prazo devido ao efeito da "curva J"..$^{15}$

Tendo-se em mente o efeito da política monetária sobre o nível de produção e emprego, sob câmbio flutuante e conversibilidade da conta de capitais, uma depreciação do câmbio nominal e real tende, inicialmente, a reduzir as exportações líquidas, de forma que ela terá um efeito inicial negativo sobre o nível de atividade econômica.

A segunda razão que Tobin (1978) nos chama a atenção é que numa economia aberta o saldo da balança comercial se torna um componente fundamental na determinação da demanda agregada da economia. Este fato abre a possibilidade de que um estímulo expansionista à demanda agregada de um determinado país imponha um choque deflacionário aos seus parceiros comerciais, via reduções (desvalorizações) contínuas das taxas de câmbio. Portanto, as autoridades monetárias podem se ver obrigadas a evitar, ou reduzir, o uso da taxa de câmbio como forma de estimular o nível de emprego doméstico.

A terceira razão apontada está relacionada ao fato de que os governos nacionais não podem ser indiferentes às mudanças nos valores de suas taxas de câmbio, uma vez que tais mudanças têm impactos nas indústrias domésticas, setores competitivos de importação e exportação, dentre outros, ou seja, sobre o nível de produto (no nível macroeconômico) e competitividade (no nível microeconômico).

A quarta razão está relacionada à idéia de que no regime de câmbio flexível é possível o isolamento das economias domésticas com relação aos choques ocorridos sobre a demanda de exportação ou importação. Ao contrário de Friedman (1953) e Johnson (1972), Tobin (1958) não acredita em tal possibilidade, a menos que a condição de Marshall-Lerner seja atendida, a qual é improvável de ocorrer no curto prazo.

E finalmente, as mesmas operações de arbitragem que limitam a autonomia do Banco Central no regime de câmbio fixo, devido à paridade descoberta da taxa de juros, podem também limitá-la no regime de câmbio flutuante. Isso porque nem sempre o Banco Central será capaz de criar expectativas de depreciação cambial que sejam consistentes com a taxa de juros desejada.

\footnotetext{
${ }^{15}$ O efeito da "curva J" implica que o impacto de uma depreciação cambial sobre a balança comercial é negativo. Uma depreciação do câmbio tende, inicialmente, a reduzir as exportações líquidas, de forma que ela terá um efeito inicial recessivo sobre o nível de atividade econômica. Esse fato pode levar os agentes econômicos a terem a idéia de que a depreciação cambial não foi suficiente, levando-os a terem uma expectativa de uma nova depreciação. Tal expectativa levará os especuladores a comprarem divisas, o que irá produzir uma efetiva depreciação da taxa de câmbio, confirmando a expectativa inicial (idéia de profecia auto-realizável). Para evitar essa possibilidade de bolha no mercado de câmbio, as autoridades podem se ver obrigadas a manter altas taxas de juros, o que gerará efeitos nocivos sobre o nível de produto (Oreiro, 2004).
} 
No contexto dos argumentos aqui desenvolvidos, vemos que independentemente do regime cambial adotado por determinada economia, a mobilidade de capitais tem a capacidade de reduzir a capacidade dos formuladores de política monetária em executar políticas domésticas, seja ela com vistas a manter a estabilidade ou paridade cambial ou com o objetivo de manter um elevado nível de renda e emprego. ${ }^{16}$

\section{FLUXOS DE CAPITAIS, PROFECIAS AUTO-REALIZÁVEIS E A POSSIBILIDADE DE CRISES CAMBIAIS ${ }^{17}$}

O sistema financeiro internacional tem vivenciado grande turbulência, notadamente no período que se sucedeu ao colapso do sistema de Bretton Woods em 1971. Soma-se a este fato a intensa mobilidade de capitais - característica marcante das duas últimas décadas - que tornou as economias nacionais, principalmente a dos países emergentes, em particular, mais vulneráveis à choques externos e crises cambiais.

Algumas dessas crises cambiais, como a da Europa (1992-93) e a do Sudeste Asiático (1997-98), são explicadas, dentro de uma ampla literatura a respeito de crises cambiais, como resultado de "profeciais auto-realizáveis", ou seja, mudanças autônomas e espontâneas nas expectativas dos agentes econômicos a respeito da capacidade do país honrar os seus compromissos externos sem a ocorrência de nenhuma ruptura com o regime de política econômica adotado pelo mesmo. ${ }^{18}$

Dentro da literatura de crises cambiais, são os "modelos de segunda geração" que enfatizam a idéia de profecias auto-realizáveis. ${ }^{19}$ De acordo com estes

\footnotetext{
${ }^{16}$ Para as circunstâncias e características específicas de um país para adoção de regimes cambiais, fixos, flexíveis ou intermediários, veja Frankel (1999).

${ }^{17}$ Muitos dos argumentos aqui desenvolvidos estão largamente baseados em Oreiro (2004).

${ }^{18}$ Essa mudança de expectativas dos investidores internacionais acaba por gerar as condições objetivas necessárias para que o país se veja obrigado a mudar o seu regime de política econômica (como o fim de um regime de câmbio fixo) ou acabe por declarar default dos pagamentos de suas obrigações externas e (ou também) internas. Autores como Krugman (1998) sustentam que a crise asiática não pode ser explicada nem pelos modelos de primeira geração nem pelos de segunda geração (os quais enfatizam a ocorrência de profecias auto-realizáveis), pois não havia nos países em crise uma deterioração nos fundamentos econômicos - tais como déficits públicos persistentes - ou ainda algum incentivo para abandonar a taxa de câmbio fixada, de modo a perseguir uma política monetária mais expansionista, mas sim a existência de uma crise financeira que precedeu a crise cambial. Para mais detalhes sobre a crise asiática, no que diz respeito aos processos de ajustes macroeconômico, microeconômico e financeiro, bem como o papel do FMI, veja Radelet e Sachs (1998 e 2001) e Krugman (1997, 1998 e 2001).

${ }^{19}$ Os artigos clássicos dos modelos de segunda geração de ataques especulativos são Obstfeld (1994, 1996), Obstfeld e Rogoff (1996) e Velasco (1996), dentre outros.
} 
modelos, o governo escolhe defender (ou não) a taxa de câmbio, tendo que enfrentar um trade-off entre flexibilidade macroeconômica de curto prazo e credibilidade de política econômica no longo prazo. A razão pela qual as autoridades econômicas decidem desvalorizar a taxa de câmbio pode estar relacionada, por exemplo, ao aumento no desemprego devido à rigidez para baixo na taxa de salário nominal, ao passo que o motivo principal que as levam a defender o regime de câmbio está no fato de que este é importante tanto para facilitar o comércio internacional e os investimentos quanto para controlar a dinâmica inflacionária (considerando-se que neste caso a inflação seja um problema crônico desta economia doméstica). Desta forma, o trade-off demonstrado por este tipo de modelo leva a uma escolha entre a manutenção da taxa de câmbio fixa (podendo significar inflação menor com desemprego maior) e a desvalorização da taxa de câmbio (podendo significar inflação maior e desemprego menor). Contudo, há uma região crítica dos fundamentos na qual existem equilíbrios múltiplos em decorrência do comportamento discricionário das autoridades monetárias. Neste contexto, os agentes supõem a existência de dois cenários possíveis (com ou sem desvalorização cambial) e a escolha deste cenário é realizado por sunspots, ${ }^{20}$ os quais determinam o comportamento dos agentes ao afetarem suas expectativas de desvalorização cambial. A mudança do regime cambial assumiria a forma de uma profecia auto-realizável. ${ }^{21}$

Segundo Eichengreen e Jeanne (2004), essa classe de modelos de ataques especulativos funciona bem para explicar a crise européia bem como uma das principais crises monetárias do período entre as guerras mundiais: a saída da Inglaterra do padrão-ouro em 1931. Entretanto, estes modelos não estabelecem nenhuma relação direta entre mobilidade de capitais de curto prazo e crise do balanço de pagamentos. Esta relação foi estabelecida por Rodrik e Velasco (1999), os quais mostram que o acúmulo de um grande passivo externo de curto prazo, resultante de um grande fluxo de entrada de capitais de curto prazo, pode criar as condições necessárias de uma crise cambial gerada por profecias auto-realizáveis.

A argumentação desenvolvida por Rodrik e Velasco (1999) é inspirada no modelo de "corridas bancárias" desenvolvido por Diamond e Dybvig (1983). No modelo destes autores a ocorrência de uma corrida bancária seria plenamente compatível com o comportamento racional dos agentes econômicos. A condição necessária para a ocorrência dessa corrida bancária seria a existência de um des-

\footnotetext{
${ }^{20}$ Tradução literal de sunspots: manchas solares. Dentro da literatura de crises cambiais, os sunspots são eventos não fundamentais que podem gerar mudanças do regime cambial e da política econômica doméstica sem vínculo com os fundamentos de uma determinada economia.

${ }^{21}$ A lógica da crise cambial, no contexto dos modelos de segunda geração, desta forma, apóia-se basicamente na idéia de que o custo de manutenção do regime de câmbio é uma função crescente da expectativa de desvalorização cambial. Se o custo de manutenção da política econômica superar o benefício percebido da manutenção do mesmo, então o governo será levado a abandoná-lo.
} 
casamento de prazos (e liquidez) entre os ativos e passivos da firma bancária. Especificamente, se supõe que o passivo do banco é constituído por recursos exigíveis a curto prazo (demand deposits), ao passo que o ativo do mesmo é constituído por instrumentos com longo prazo de maturidade (investments). Nesse contexto, se o banco for obrigado a converter os seus ativos em meio de pagamento antes do término do prazo de maturidade dos mesmos, então ele irá incorrer numa perda de capital a qual, se for de grande magnitude, poderá tornálo insolvente.

O resultado fundamental do modelo de Diamond e Dybvig (1983) é que esse descasamento de prazos permite a obtenção de duas posições de equilíbrio, a saber: um equilíbrio com corrida bancária (equilíbrio "ruim") e um equilíbrio sem corrida bancária (equilíbrio "bom"). No caso do equilíbrio ruim, os depositantes acreditam que o banco não será capaz de cobrir os depósitos dos correntistas de tal forma que ocorre uma corrida contra o banco, cujo objetivo é sacar os depósitos o mais rapidamente possível antes que o banco seja obrigado a decretar falência. Dado que os depósitos no banco são ativos exigíveis a curto prazo, o banco, nesse contexto, é obrigado a realizar seus ativos de longa maturação para cobrir a fuga de depósitos. Contudo, a realização antecipada dos mesmos impõe uma grande perda de capital para o banco, fazendo com que o valor dos seus ativos fique menor do que o valor do seu passivo, levando-o a se tornar insolvente. Isto posto, se segue que uma expectativa compartilhada entre os depositantes de que o banco não tem recursos para cobrir todos os depósitos, termina por criar as condições objetivas necessárias para que o mesmo se torne insolvente.

No equilíbrio bom os agentes acreditam que o banco terá recursos suficientes para cobrir os depósitos de todos os correntistas. Neste sentido, os depósitos são mantidos no banco ao longo de todo o período de maturidade dos ativos que foram adquiridos pelo mesmo com os referidos depósitos. No final desse prazo de maturidade, o banco realiza esses ativos por um valor igual ao montante de recursos tomados de empréstimo dos correntistas acrescido da rentabilidade líquida dos ativos em consideração. Os depósitos são então devolvidos aos correntistas e o banco ainda aufere um lucro que remunera o serviço de transformação de maturidades realizado pelo mesmo. Nesse contexto, a expectativa compartilhada de que o banco terá recursos suficientes para honrar seus compromissos junto aos depositantes gera as condições necessárias para a realização dessa expectativa.

Rodrik e Velasco (1999) desenvolvem um trabalho conceitual e empírico para a avaliação do efeito dos fluxos de capitais de curto prazo. Em um modelo simples de determinação conjunta da maturidade e custo de empréstimos externos é ressaltado o papel das crises originadas de profecias auto-realizáveis. Neste modelo, o ingresso de capitais de curto prazo numa determinada economia pode gerar um problema similar ao da "corrida bancária" desenvolvido por Diamond e Dybvig (1983), onde os capitais de curto prazo (entendidos como empréstimos 
e aplicações de curto prazo) são semelhantes aos depósitos bancários no que se refere ao prazo de maturidade. Como destaca Oreiro (2004), esses capitais são utilizados para o financiamento da aquisição de ativos financeiros (como por exemplo, ações) ou da aquisição de ativos reais (por exemplo, imóveis ou projetos de investimento) e, caso tenhamos a realização antecipada desses ativos, temos como resultado uma perda de capital para os seus detentores devido à menor liquidez e/ou ao maior prazo de maturidade dos mesmos. Similarmente ao caso de corridas bancárias de Diamond e Dybvig (1983), a solvência dos tomadores de recursos de curto prazo depende das expectativas dos investidores internacionais. ${ }^{22}$

Se o regime cambial adotado por uma determinada economia doméstica for o de câmbio fixo, as expectativas pessimistas dos agentes econômicos internacionais poderão fazer com que ocorra uma reversão súbita (sudden stop $)^{23}$ dos fluxos de capitais, a qual gerará perda de divisas por parte da autoridade monetária. Caso essa perda de reservas chegue a um nível crítico, ocorrerá uma maxidesvalorização cambial, onde teremos o abandonamento do sistema de câmbio fixo.

No caso do regime de câmbio flutuante, a reversão súbita dos fluxos de capitais de curto prazo irá resultar numa grande depreciação da taxa de câmbio nominal, aumentando os problemas financeiros dos tomadores da economia doméstica e gerando pressões inflacionárias (efeito pass through) devido ao aumento dos preços em moeda doméstica dos bens tradeables e ao aumento dos custos de produção dos bens não tradeables que utilizam insumos importados para a sua produção.

A desvalorização do câmbio advinda da mudança do regime cambial no primeiro caso, ou o forte movimento de depreciação do câmbio nominal no regime de câmbio flutuante deverão resultar, no curto prazo, numa redução do nível de

\footnotetext{
${ }^{22}$ Caso as expectativas desses agentes econômicos internacionais sejam "otimistas", ou seja, se os investidores acreditarem na capacidade dos tomadores domésticos de honrarem os seus compromissos externos, então estes tomadores domésticos poderão honrar os seus compromissos externos efetivamente. Desta forma, os tomadores domésticos poderão "carregar" as suas posições até o prazo de maturidade de seus ativos, pagando o valor do empréstimo, juros e realizando algum lucro. No entanto, se as expectativas dos agentes econômicos internacionais forem "pessimistas" e, dessa forma, não acreditarem na capacidade dos tomadores domésticos de honrarem os seus compromissos contratuais, então eles irão exigir o pagamento dos empréstimos realizados no prazo de vencimento estipulado, negando-se a refinanciar as posições dos tomadores domésticos. Esse fato poderá obrigar os tomadores domésticos a realizarem vendas antecipadas de ativos, gerando uma grande redução nos preços dos mesmos.

${ }^{23}$ A definição de sudden stop, ou parada súbita, segundo Calvo (1998 e 1999), é de que seja uma parada não antecipada do influxo de um grande volume de capitais. Para ele, mudanças negativas no influxo de capitais são perigosas para a maioria das economias domésticas, uma vez que podem resultar em bancarrota, destruição de capital humano e canais de créditos locais (estes últimos aspectos são explicados com maiores detalhes em Calvo, 1998).
} 
atividade econômica. O efeito de curto prazo de uma desvalorização/depreciação do câmbio sobre o saldo da balança comercial é contracionista devido ao efeito da "curva J". ${ }^{24}$ Além disso, a demanda agregada dos bens domésticos irá sofrer, inicialmente, uma redução como resultado da desvalorização/depreciação da taxa de câmbio.

Calvo (2001) nos chama a atenção de que sob a circunstância da deterioração da posição financeira das empresas domésticas devido à redução do valor de mercado de seus ativos e ao aumento do valor de suas obrigações externas em moeda doméstica poderá resultar em uma "evaporação de crédito", onde esta se configura em uma situação na qual o volume disponível de crédito para o financiamento das atividades de rotina das empresas se reduz drasticamente. Com isto, as empresas de uma determinada economia doméstica serão obrigadas a reduzir o nível de produção devido à escassez de recursos disponíveis para o financiamento de seu capital de giro..$^{25}$

Baseando-nos nas argumentações expostas até agora, podemos ver que os fluxos de capitais de curto prazo contribuem para aumentar a fragilidade externa das economias domésticas à medida que mudanças súbitas das expectativas dos investidores internacionais podem resultar numa redução drástica do nível de desempenho macroeconômico desses países em qualquer tipo de regime cambial adotado.

Para a ocorrência da reversão súbita dos fluxos de capitais de curto prazo depende-se, contudo, da formação de uma "convenção pessimista" entre os investidores internacionais.

Uma explicação ortodoxa na formação dessa "convenção pessimista" está baseada na idéia de que este consenso só pode resultar da adoção de políticas macroeconômicas inconsistentes ou da existência de um sistema financeiro doméstico inadequadamente regulado. Neste sentido, o risco de reversões súbitas nos fluxos de capitais de curto prazo poderia ser minimizado - ainda que não completamente eliminado - pela adoção de um arcabouço macroeconômico consistente o qual englobaria, por exemplo, baixas taxas de inflação, equilíbrio orçamentário e baixo déficit em transações correntes.

\footnotetext{
${ }^{24}$ Veja nota de rodapé número 15.

${ }^{25}$ Para Calvo (2001, p. 102), “[...] esse exemplo mostra que as dificuldades de rolagem das dívidas, mesmo quando localizadas em um único setor, podem se espalhar por toda a economia, resultando na evaporação do crédito e em uma perda considerável de bem-estar”. No artigo de Calvo (2001) é desenvolvido um modelo simples, baseado no aspecto temporal da maturação do investimento. Esse modelo explica o que colabora para a ocorrência do colapso da produção, da crise monetária e da crise financeira. A intuição é que a reversão do fluxo de capitais esvazia a liquidez, gerando uma corrida aos bancos. A queda no crédito força uma interrupção dos investimentos, cujos projetos estavam sendo financiados anteriormente. O valor da liquidação desses projetos é baixo (ou zero), o que gera uma perda na produção. Nesse ponto do modelo há um déficit em conta corrente que requer uma depreciação real para retornar ao equilíbrio; por essa razão, ocorre uma desvalorização da moeda.
} 
Em uma análise empírica da crise das economias do Sudeste Asiático (Indonésia, Malásia, Tailândia, Filipinas e Coréia do Sul), Radalet e Sachs (2001) nos apontam elementos essenciais, como o pânico financeiro, para explicá-la. Esses países apresentavam superávit ou equilíbrio nas contas fiscais do governo central, bem como baixas taxas de inflação. Nesse sentido, a tese ortodoxa de que a mudança nas expectativas dos investidores internacionais é resultado de políticas macroeconômicas inadequadas não é consistente com a experiência dos países afetados pela crise que decorreu nestes países. ${ }^{26}$

Explicações alternativas para a emergência de um consenso pessimista estão fundamentadas na idéia de comportamento manada (herding behaviour), contágio, e a ação de sunspots.

O comportamento manada (herding behaviour) é definido como uma situação na qual o comportamento de um determinado grupo de agentes é imitado por todos os demais. ${ }^{27}$

Neste sentido, uma mudança nas expectativas dos agentes econômicos, levando-os a acreditar numa desvalorização cambial, provoca uma mudança nas carteiras dos mesmos, que deixam de demandar títulos domésticos (denominados em moeda local) para demandar títulos externos (denominados em dólares). Este choque inicial é amplificado pelo comportamento imitativo de outros agentes que leva a um ataque especulativo maior que o inicialmente provocado pela mudança na desvalorização esperada. Portanto, os agentes provocam um ataque especulativo desconsiderando os "fundamentos" da economia.

Segundo Licha (2000), a volatilidade cambial está associada à existência de comportamento de manada. Assim, quando aumenta a incerteza nos mercados financeiros os agentes tendem a prever a psicologia do mercado (Keynes, 1936) e não os lucros esperados dos ativos, tornando voláteis os mercados financeiros. Nesse sentido, as crises cambiais são originadas em mudanças nas expectativas

\footnotetext{
${ }^{26}$ Krugman (1997) defende a idéia de que a crise asiática é um reflexo dos riscos excessivos e mesmo furtivos dos bancos, que ganharam acesso aos depósitos domésticos e estrangeiros em virtude da garantia do Estado sobre estes depósitos, ou seja, a reversão súbita dos fluxos de capitais foi o resultado da percepção por parte dos investidores internacionais da elevada fragilidade do setor bancário desses países. Na mesma linha de argumentação de Krugman (1997), Stiglitz (2002) aponta que a existência de sistemas bancários inadequadamente regulados e, portanto, sujeitos ao problema de moral hazard, é mais uma razão pela qual os países que se defrontam com essa situação devem procurar desencorajar os fluxos de entrada de capitais de curto prazo, pois o acesso fácil aos mercados internacionais de capitais aumenta o grau de alavancagem dos bancos domésticos, permitindo aos mesmos realizarem um volume muito maior de empréstimos arriscados.

${ }^{27}$ Krugman (1997) nos diz que "In general, herding can be exemplified by the result found by Shiller's remarkable survey of investor during the 1987 stock market crash: the only reason consistentently given by those selling stocks for their actions was the fact that prices are going down. In the context of a currency crisis, of course, such behavior could mean that a wave of selling, whatever its initial cause, could be magnified though sheer imitation and turn, quite literally, into a stampede out of the currency" (Krugman, 1997, p. 6).
} 
de desvalorização (que constituem sunspots) e a fuga de capitais é amplificada pela existência de comportamento manada (herding behaviour). Nesse contexto, o comportamento dos outros investidores é mais importante do que a política econômica. ${ }^{28}$

Oreiro (2004) destaca que o comportamento manada pode resultar de dois mecanismos. O primeiro mecanismo, enfatizado por Banerjee (1992), estabelece que "fazer o que todo mundo faz" é uma atitude racional por parte dos agentes econômicos num contexto em que os mesmos acreditam que os demais agentes podem ter mais informações do que as possuídas pelos primeiros.

O segundo mecanismo, enfatizado por Schaferstein e Stein (1990), parte do princípio de que existem ganhos de reputação associados ao seguimento da opinião média prevalecente no mercado. Tais ganhos são particularmente relevantes num ambiente institucional caracterizado por (i) separação entre propriedade do capital e gestão das empresas e (ii) informação assimétrica a respeito da "qualidade média" dos gerentes de empresas. Nesse sentido, no ambiente institucional vigente é melhor para os gerentes de empresas e carteira "fracassar junto com o mercado do que vencer contra ele" (Keynes, 1936, p. 130).

Dentro da literatura sobre comportamento manada, os autores que demonstram sua relação com a reversão súbita de capitais (sudden stops) de curto prazo para países emergentes são Calvo e Mendoza (1999). Estes autores nos mostram que os investidores internacionais "seguem" o mercado, ao invés de despenderem tempo e dinheiro para fazerem sua própria avaliação dos fundamentos de cada economia que compõem seu portfólio. Isto ocorre porque os gestores dos fundos de investimento internacional se defrontam com um "custo de reputação" associado à obtenção de um retorno médio menor do que de determinado portfólio de referência. Quando os gestores desse portfólio de referência mudam sua composição retirando recursos de um determinado país, outros gestores podem imitá-los, caracterizando uma reversão súbita dos fluxos de capitais de curto prazo. $^{29}$

No restante de seu trabalho, Calvo e Mendoza (1999) demonstram através de seu modelo que a decisão de imitar um portfólio de referência pode ser uma decisão racional por parte dos investidores internacionais em um contexto que:

\footnotetext{
${ }^{28}$ Isto posto, eventos não fundamentais (os chamados sunspots), como rumores, podem desencadear uma crise externa sobre as economias dos países tanto sob câmbio fixo quanto flutuante (ou mesmo em regimes intermediários). Além disso, esta crise externa pode ser amplificada pela existência de comportamento manada (herding behaviour) dos investidores internacionais. Nesse sentido, quanto maior a vulnerabilidade externa de um país mais suscetível o mesmo estará à ação dos sunspots.

${ }^{29}$ Calvo e Mendoza (1999, p. 2) desenvolvem a idéia de contágio, definindo-a como "a situation in which utility-maximizers investors choose not to pay for information that would be relevant for their portfolio decisions - thereby making them susceptible to react to country-specific rumors - or in which investors optimally choose to mimic arbitrary "market" portfolios [...]".
} 
a) existe um custo fixo para a obtenção de informações relevantes sobre a situação do país; b) existem restrições institucionais ou legais para a venda de ativos a descoberto (o que o autor chama de short-selling constraints) e c) há um grande número de países emergentes com características "parecidas” na avaliação dos investidores internacionais. Dessa forma, a decisão ótima de um investidor internacional racional é de não coletar informações a respeito de um determinado país onde está aplicado parte de seus recursos, pois o ganho possível de se obter com esta informação é inferior ao custo despendido para tê-la.

\section{FLUXOS DE CAPITAIS DE CURTO PRAZO \\ E A POSSIBILIDADE DE PROFECIAS AUTO-REALIZÁVEIS: \\ O MODELO DE RODRIK E VELASCO (1999)}

Rodrik e Velasco (1999) realizam uma análise teórica e empírica ${ }^{30}$ para avaliarem os efeitos dos capitais de curto prazo sobre uma determinada economia. Estes autores, através de um modelo de determinação conjunta dos custos e da maturidade de empréstimos externos, realçam o papel das crises originadas de profecias auto-realizáveis.

Do ponto de vista teórico, Rodrik e Velasco (1999) constroem um modelo baseando-se em fatos estilizados, de como um volume excessivo de dívida externa de curto prazo de um país pode torná-lo vulnerável às mudanças súbitas nas expectativas dos credores internacionais.

Supõe-se no modelo uma economia aberta e pequena cuja população é composta por um único tipo de agente investidor-consumidor, o qual vive por três períodos: 0 (período de planejamento), 1 e 2 . Este agente possui acesso a projetos de investimento de tamanho fixo: investindo $k$ unidades de um produto tradeable no período 0 , resultando em $R k$ unidades do mesmo produto no período 2 , onde $R>1$. Contudo, esse projeto é ilíquido, no sentindo de que se um determinado montante $l \leq k$ é "liquidado" no período 1 , somente renderá $\rho l$ unidades, onde $\rho<1$.

Para financiar este projeto os indivíduos desta economia podem realizar empréstimos no exterior, onde, em um mundo sem riscos, a taxa de juros é zero. Os credores externos são neutros em relação ao risco e desejosos de emprestarem

\footnotetext{
${ }^{30}$ Rodrik e Velasco (1999) realizam uma análise empírica abrangendo 32 países emergentes no período de 1988 a 1998, objetivando verificar as causas e conseqüências da existência de dívidas em moeda estrangeira de curto prazo. Estes autores encontraram que a relação entre dívida externa de curto prazo e reservas externas é um previsor robusto de crises financeiras. Países com obrigações de curto prazo em bancos estrangeiros que excedam as reservas têm propensão três vezes maior de experimentarem uma súbita e massiva reversão dos fluxos de capitais.
} 
em duas formas de maturidades: empréstimos de curto prazo $(\mathrm{CP})$ por um único período e empréstimos de longo prazo (LP), cujo vencimento é em dois períodos. Assume-se também que estes empréstimos estrangeiros têm suas garantias dadas pelas ações das empresas. Desta forma, os investidores não podem realizar empréstimos superiores a $k$ no período 0 , e o principal de sua dívida não pode exceder o tamanho do investimento residual (a parte não "liquidada") nos períodos subseqüentes.

Supõe-se que no período 0 o investidor possui um montante $d \leq k$ e dívidas de curto prazo, e um montante $k-d$ de empréstimos de longo prazo. Quando quer que seja que $d>0$, os credores escolhem não rolarem a dívida de curto prazo do período 1. Se isso ocorrer, Rodrik e Velasco (1999) dizem que uma "corrida" sobre as dívidas de curto prazo ocorreu.

O consumo só ocorre no período 2 do modelo. Neste ponto, o investidor recolhe o lucro do seu investimento, paga uma fração inicial do empréstimo que não foi paga no período 1, e então consome. Assume-se que a função utilidade do consumidor seja linear. ${ }^{31}$

Rodrik e Velasco (1999) consideram que esta configuração simples do modelo possui todos os ingredientes necessários para a existência de equilíbrios múltiplos. A forma mais simples para estes autores demonstrarem tal possibilidade é tomando o montante $d$ de dívidas de curto prazo como, inicialmente, exógeno. Supõe-se também que o investidor é onerado pela taxa de juros internacional 0 para os empréstimos de curto e longo prazo.

De acordo com os pressupostos supracitados, Rodrik e Velasco (1999) encontram dois equilíbrios. No primeiro equilíbrio, chamado de "otimista", os credores internacionais rolam os empréstimos $d$ no período 1 , de forma que nenhum dos investimentos precisa ser "liquidado" no período. O investidor tem um renda $R k$ no período 2 , e dívidas de $d+(k-d)=k$. Esse investidor paga todas as suas dívidas e consome $(R-1) k$.

Considerando $d$ muito pequeno, esse não é o único resultado possível. Suponha que no período 1 os credores reivindiquem o cumprimento dos seus empréstimos, antecipando que se eles os rolarem, os mesmos não seriam pagos no período 2. ${ }^{32}$ Rodrik e Velasco (1999) consideram que esse equilíbrio "pessimista” se transformaria em uma crise de profecia auto-realizável nas seguintes circunstâncias: sem a rolagem da dívida, o investidor tem que liquidar $l \frac{d}{\rho}$, de forma que o serviço da dívida de curto prazo no período 1 seja cumprida. Isso

\footnotetext{
${ }^{31}$ Rodrik e Velasco (1999) descrevem o modelo como sendo aplicável somente à dívida privada. Contudo, estes autores advogam que o modelo dá margens a interpretações plausíveis de forma que sirva a uma análise de dívida pública também.

${ }^{32}$ Tal expectativa poderia ocorrer dado o rumor (sunspots) no mercado externo de insolvência futura do país, por exemplo.
} 
significa que no período 2 o investidor terá como resultado uma renda de $R\left(k-\frac{d}{\rho}\right)$, e dívidas de $(k-d)$. Se esta última quantidade é muito grande ${ }^{\left(d>\left(\frac{R-1}{R-\rho}\right) \rho k\right)}$, então o investidor não terá recursos suficientes para pagar os detentores de dívidas de longo prazo, e os detentores de dívidas de curto prazo estarão felizes porque eles conseguiram resgatar seus empréstimos no período 1 . Neste equilíbrio a firma doméstica irá à bancarrota deixando dívidas não pagas e nenhum lucro.

Esse segundo equilíbrio possui, em termos de bem-estar geral, claramente uma situação inferior para todos os envolvidos no modelo. Os credores de empréstimos de longo prazo não são integralmente pagos. Os investidores não consomem nada, em contraste com o nível de consumo positivo obtido no equilíbrio otimista. Desta forma, "corridas" contra a dívida de curto prazo têm efeitos reais. Esses efeitos, por sua vez, têm importantes conseqüências em termos de bem-estar dos indivíduos. ${ }^{33}$

Analisando o modelo de Rodrik e Velasco (1999) e sem nos prendermos ao formalismo matemático, notamos que a quantidade de dívida de curto prazo escolhida afeta tanto a taxa de juros para empréstimos de curto prazo, quanto a taxa de juros dos empréstimos de longo prazo. ${ }^{34}$ Uma das principais conclusões do modelo de Rodrik e Velasco (1999) é de que as dívidas de curto prazo são potencialmente perigosas para a economia, dado que requerem liquidações de ativos com custos elevados no caso de uma "corrida", a qual ocorre com probabilidade positiva no modelo.

Muitas são as razões colocadas pelos autores do modelo para explicarem os porquês das distorções sofridas pelos agentes ao realizarem empréstimos arriscados, de forma que coloquem o bem-estar privado e social em xeque. Rodrik e Velasco (1999) elegem as seguintes razões:

a) os agentes individuais que buscam empréstimos externos falham em levar em conta o aumento do rating de risco-país que possivelmente resultará do aumento do volume dos empréstimos de curto prazo;

\footnotetext{
${ }^{33}$ Os custos de liquidação física no modelo representam uma forma de metáfora para os muitos custos envolvidos no caso de uma situação de iliquidez das firmas. Outros desarranjos macroeconômicos associados são: projetos inacabados ou depreciados muito rapidamente, a escassez de recursos paralisa os empreendimentos, mudanças bruscas na demanda e nos preços relativos podem levar à falência de outras firmas e investimentos que então seriam considerados viáveis. Todos esses desarranjos estiveram presentes em maior ou menor grau, por exemplo, na crise asiática.

${ }^{34}$ Isso ocorre porque o grande volume de obrigações de maturidade de curto prazo reduz a probabilidade de que os credores de obrigações de longo prazo sejam pagos. Em um modelo mais geral, em que devedores de dívidas de curto e longo prazo fossem diferentes conjuntos de agentes engajados em diferentes tipos de atividades econômicas, estes autores consideram que as ações dos agentes devedores de curto prazo fazem com que haja "externalidades negativas" sobre os devedores de longo prazo. Essa externalidade poderia operar, por exemplo, através da disponibilidade de reservas do Banco Central: um aumento na dívida externa de curto prazo reduz o estoque de reservas que os agentes "antecipam" estar disponível para cumprir os serviços da dívida de longo prazo, fazendo com que as obrigações cuja maturidade seja de longo prazo se tornem mais arriscadas do ponto de vista dos credores.
} 
b) devido à assimetria de informações, os credores internacionais não podem distinguir entre indivíduos/firmas (neste modelo) diferentes, e os tratam com riscos iguais; e

c) a expectativa de ser "socorrido" em um momento de crise por organismos multilaterais, ou pelo próprio governo, pode encorajar comportamentos imprudentes por parte dos indivíduos/firmas;

O modelo de Rodrik e Velasco (1999) traz ainda outras importantes implicações:

d) "corridas bancárias" por parte dos credores externos somente podem ocorrer quando os investidores tomam grandes montantes de dívidas de curto prazo;

e) quanto maior o estoque de dívidas de curto prazo, maior o tamanho da "corrida" dos credores externos contra os investidores domésticos;

f) quando maior o estoque de dívidas de curto prazo, maiores são as conseqüências em termos reais de uma "corrida" (em termos de custos de liquidação de ativos e redução de consumo e produto); e

g) incentivos "distorcidos" podem levar os investidores a realizarem empréstimos de curto prazo, mesmo estes sendo socialmente custosos. Desta forma, talvez fosse o caso de que as políticas públicas atuassem no sentido de desencorajarem este tipo de empréstimo.

\section{HERDING BEHAVIOUR E A VOLATILIDADE DO MERCADO DE CÂMBIO: O MODELO DE LICHA (2000)}

Licha (2000) apresenta um modelo macroeconômico que descreve os efeitos multiplicadores que mudanças nas expectativas de depreciação/desvalorização do câmbio têm sobre o fluxo de capitais em economias emergentes. Esse efeito ocorre devido à existência de cascatas informacionais, onde os agentes passam a guiar-se pela história das transações realizadas, ignorando qualquer informação nova e gerando um comportamento manada (herding behaviour). ${ }^{35}$

No modelo de Licha (2000) existe um grande número de dois tipos de agentes: a) agentes externos que aplicam seus capitais no país doméstico e geram uma entrada de capitais (E) e b) agentes internos que retiram seus capitais do país e geram uma saída de capitais (S).

\footnotetext{
${ }^{35}$ Avery e Zemsky (1998) descrevem uma situação de cascata informacional como aquela em que o comportamento imitativo dos agentes pode impedir o fluxo de informações em uma economia quando os agentes econômicos atuam seqüencialmente, ao invés de simultaneamente. Com estes atos seqüenciais, as decisões mais recentes podem ter um efeito desproporcional sobre os resultados de longo prazo na economia. Uma pequena preponderância de informações públicas é suficiente para induzir todos os agentes a seguirem o líder do mercado, ignorando completamente suas informações privadas.
} 
A escolha é seqüencial, de forma que a cada instante ( $\mathrm{t}$ ) é selecionado um agente. Em cada momento a aplicação é unitária, entrando ou saindo uma unidade de capital. O modelo analisa como os tipos de agentes são selecionados, estudando a estrutura assintótica dos movimentos de capitais.

Seja $n_{t}=n_{t}^{E}+n_{t}^{S}$ o fluxo total de capitais até $\mathrm{t}, n_{t}^{E}$ a entrada de capitais até t, $n_{t}^{S}$ a saída de capitais até t e $x_{t},=n_{t}^{E} / n_{t}$ a proporção da entrada de capitais em relação ao fluxo total até t.

Isto posto, a entrada de capitais até t é determinada pelo seguinte processo:

$$
n_{t}=n_{t+1}^{E}+v \quad v_{t}=\left\{\frac{\text { Assume } 1 \operatorname{com} P_{t}}{\text { Assume } 0 \operatorname{com} 1-P_{t}}\right.
$$

onde:

$v_{t}=$ variável aleatória;

$p_{1}$ probabilidade (calculada em t-1) de que em t seja selecionada um agente externo que promova uma entrada de capitais. Esta probabilidade é uma função de $x_{t-1}$.

A dinâmica de $x_{t}$ será dada pela seguinte equação:

$$
x_{t}=x_{t-1}+\frac{1}{n_{t}}\left[p_{t}-x_{t-1}\right]+\frac{1}{n_{t}} u_{t}
$$

onde: $u_{t}=v_{t}-p_{t}$. A dinâmica de $x_{t}$ depende da atração da entrada de capitais (dada por $\left.p_{t}-x_{t-1}\right)$ e de uma perturbação $\left(u_{t}\right)$.

No modelo de Licha (2000) todos os agentes recebem uma mensagem $y_{t}$ sobre a taxa de retorno esperada da entrada de capitais que pode ser decomposta num sinal $S_{t}$ (associado aos fundamentos da economia doméstica) e um ruído $m_{t}$ :

$$
y_{t}=s_{t}-m_{t}
$$

Os agentes não conhecem os valores de $s$ e $m$. Contudo, sabem que estes valores têm médias e variâncias constantes. Ou seja:

$$
\begin{aligned}
& s_{t} \sim N\left(\bar{i}, \sigma^{2}\right) \\
& m_{t} \sim N\left(0, \tau^{2}\right)
\end{aligned}
$$

Assim como Calvo e Mendoza (1999), Licha (2000) considera que em países emergentes os agentes globalizados não utilizam suas informações de mercado para tomarem suas decisões, mas imitam as decisões dos outros agentes. Esse comportamento imitativo supõe a existência de cascata informacional na entrada de capitais e pode ser modelado a partir dos seguintes supostos:

a) se os agentes não utilizam suas informações isso é devido à relação ruído-sinal da mensagem ser muito elevada de forma que as novas mensagens não afetem as expectativas dos agentes externos;

b) para representar o comportamento imitativo dos agentes considera-se que $\bar{i}$ é uma função crescente da proporção da entrada de capitais no fluxo total. Em especial, considera-se que: 


$$
\overline{i_{t}}=\hat{i}+\alpha x_{t-1}
$$

onde $\hat{i}$ (taxa de retorno esperada se não existe entrada de capitais) e $x$ (parâmetro que representa o grau de imitação dos agentes) são definidos positivos. A equação (4) supõe que existe uma externalidade de rede associada à entrada de capitais. $^{36}$

Como se supõe que o país em análise seja pequeno, a fuga de capitais não afeta a taxa de retorno esperada da saída de capitais $\left(r_{t}\right)$. Então:

$$
r_{t}=\hat{r}+d_{t}
$$

onde $\hat{r}$ é a taxa de retorno esperada da saída de capitais (dada uma aplicação em dólar) e $d_{t}$ é a taxa de desvalorização esperada em t. Considera-se que existe incerteza a respeito de $d_{t}$. Aos efeitos de realizar uma apresentação paramétrica do modelo supõe-se que $d_{t}$ possui uma função de distribuição uniforme $\left(\mathfrak{f}\left(d_{t}\right)\right)$ no intervalo $(-\mathrm{z}, \mathrm{z})$, onde z é um parâmetro de suporte. ${ }^{37}$

A cada momento ou um agente externo promove uma entrada de uma unidade de capital com rendimento esperado $i_{t}$ ou um agente interno gera uma saída de uma unidade com rendimento esperado $r_{t}$ (dada uma realização de $d_{t}$ ).

Consideram-se ainda mais quatro supostos:

a) os ativos domésticos e externos são substitutos imperfeitos o que limita a arbitragem entre mercados, $\log 0 \lambda_{t}$ (o diferencial da taxa de retornos esperados) não tende a ser zero;

b) a expectativa de desvalorização pode ser suficientemente grande em relação ao diferencial de retornos esperados de forma que afete a seleção do tipo de agente que vai tomar as decisões. Em particular, z $>2 \mid \Delta_{t}$, $\mid$. Onde $\Delta$ é o diferencial das taxas de retorno esperadas, sem considerar a taxa de desvalorização esperada;

c) se $\lambda_{t}>0$ um agente externo promove uma entrada de capitais;

d) se $\lambda_{t} \leq 0$ um agente interno promove uma saída de capitais.

Seja $p_{t}$ a probabilidade de que na próxima escolha aconteça uma entrada de capitais, calculada em $\mathrm{t}-1$, de que $\mathrm{t}$ seja escolhido um agente externo, então $p_{t}=$ $\operatorname{Pr}\left(\lambda_{t}>0\right)$ e :

$$
p_{t}=\int_{-z}^{\Delta}\left(\frac{1}{2 z}\right) d d_{t}=\frac{z+\hat{i}+\hat{r}+\alpha x_{t-1}}{2 z}
$$

Pode-se notar que $p_{t}$ depende diretamente de $x_{t-1}$ e que no modelo existe um mecanismo de realimentação positivo entre $\lambda_{t}$ e $x_{t}$, pois uma redução no diferen-

\footnotetext{
${ }^{36} \mathrm{O}$ conceito aqui empregado de externalidade de rede significa que há uma dependência da entrada de capitais externos de um investidor internacional em relação às decisões semelhantes de outros investidores.

${ }^{37}$ Todos os agentes observam a mesma distribuição.
} 
cial das taxas de retorno esperadas provoca uma fuga de capitais que amplifica a redução inicial. Desta forma, um aumento na taxa de desvalorização esperada (que afeta o diferencial das taxas de retorno esperadas) possui um efeito multiplicador sobre a saída de capitais.

A partir da equação (6) Licha (2000) calcula o ponto fixo do processo de escolha:

$$
\xi=\frac{z+\hat{i}-\hat{r}}{2 z-\alpha}
$$

onde $\xi$ é um atrator do processo pois, dados os supostos realizados, $d p_{t}(\xi) /$ $d x_{t-1}=\alpha / 2 \mathrm{z}<1$. Em $x_{t}$ que converge assintoticamente para $\xi$ e a taxa de convergência do processo é $t^{-1 / 2}$.

De uma maneira geral, os modelos de ataques especulativos analisam como os fundamentos e/ou sunspots afetam o comportamento de $d_{t}$. O objetivo do trabalho de Licha (2000) não é analisar esses determinantes, mas estudar um mecanismo que explique a volatilidade de capitais provocada pela mudança do regime cambial. Por isso, Licha (2000) considera que a mudança da função distributiva da taxa de desvalorização esperada é determinada exogenamente e este autor a trata em dois casos: uma mudança na média de $d_{t}$ e uma mudança na variância de $d_{t}$.

Como o nosso objetivo na presente subseção é mais geral no que tange às possibilidades de crises cambiais, consideramos suficiente a apresentação do caso da mudança da variância de $d_{t}$. Nesse sentido, supõe-se que a variância da desvalorização esperada aumente, mas não o seu valor médio. Para isto, seja [-2z,2z] o suporte para $d_{t}$. A dinâmica de $x_{1}$ também apresenta uma mudança de regime. A função alocativa é:

$$
p_{t}^{2}=\frac{2 z+\hat{i}-\hat{r}+\alpha x_{t-1}}{4 z}
$$

O novo atrator fica:

$$
\xi=\frac{\hat{i}-\hat{r}+2 z}{4 z-\alpha}
$$

Um aumento da variância de $d_{t}$ também promove uma fuga de capitais neste caso.

Após a simulação do modelo e a avaliação dos seus resultados, Licha (2000) conclui que a existência de agentes econômicos imitadores faz com que o processo de conformação da estrutura dos fluxos de capitais tenha uma memória longa e que os choques afetem essa estrutura de forma permanente, explicando a volatilidade dos fluxos de capitais em países emergentes. Além disso, a falta de credibilidade do regime cambial nestes países promove flutuações no movimento de capitais de curto 
prazo que são amplificados pelos comportamentos de manada, tornando esses fluxos mais voláteis e aumentando a vulnerabilidade financeira dessas economias.

\section{COMENTÁRIOS FINAIS}

Ao longo do presente artigo, desenvolvemos argumentos que nos mostram que independentemente do regime cambial adotado e dada a volatilidade dos fluxos de capitais de curto prazo, podemos ter crises cambiais devido a fatores diversos como profecias auto-realizáveis, sunspots e herding behavior. Além disso, o regime cambial mais apropriado difere entre países e no decorrer do tempo (dados os diferentes objetivos das políticas nacionais, como preferir entre a independência de política monetária ou união monetária, por exemplo). A escolha do regime deve levar em consideração, dentre outros fatores, a elevada mobilidade de capitais e a integração internacional dos mercados financeiros, uma vez que os fluxos de capitais de curto prazo contribuem para aumentar a vulnerabilidade externa das economias domésticas à medida que mudanças súbitas das expectativas dos investidores internacionais podem resultar numa redução drástica do nível de desempenho macroeconômico sob qualquer tipo de regime cambial.

As depreciações da taxa de câmbio não são explicadas estritamente em termos dos fundamentos de uma determinada economia e a volatilidade sofrida em alguns casos de regimes de câmbio flutuante não é, de igual forma, explicada por mudanças bruscas nos fundamentos. Os mercados têm uma tendência a exibirem comportamentos de manada (herding behaviour), contágio ou a sofrerem a ação de sunspots, como procuramos apontar nas seções anteriores.

Se aceitarmos a hipótese de que um dos fatores centrais que pressionam qualquer tipo de regime cambial tem origem no grande e instável fluxo de capitais, então devem-se buscar medidas que reduzam a magnitude e volatilidade dos mesmos, quer seja através da introdução do controle de capitais - tal como sugerido recentemente para o Brasil por Paula, Oreiro e Jonas (2003) - ou como advoga Grenville (2000) e Rodrik e Velasco (1999) sugerem, através da adoção de medidas de supervisão prudenciais (como limites de empréstimos em moeda estrangeira, limite para a ação dos bancos em moeda estrangeira, dentre outros), estabelecimento das melhores práticas contábeis disponíveis, bem como de sistemas e marcos legais e corporativos.

\section{REFERÊNCIAS BIBLIOGRÁFICAS}

AGÉNOR, Pierre-Richard. Benefits and Costs of International Financial Integration: Theory and Facts. Washington, The World Bank, 2003.

AVERY, C. e ZEMSKY, P. Multidimensional Uncertainty and Herd Behavior in Financial Markets. The American Economic Review, Vol. 88, nº 4, September, 724-748.

BANERJEE, A. "A simple model of herd behavior". The Quarterly Journal of Economics, Vol. CVII, n.3. 1992. 
BATISTA JR., Paulo Nogueira. “'Globalização' Financeira e Regimes Cambiais”. Revista de Economia Política., Vol.18, n.2 (70), abr./jun. 1998.

CALVO, Guillermo A. Capital Flows and Capital-Market Crises: the simple economics of sudden stops. Journal of Applied Economics, Vol 1, nº 1, November 1998, pp. 35-54, 1998.

CALVO, Guillermo A. Contagion in emerging markets: when Wall Street is a carrier. 1999. (mimeo). . Crises de Balanço de Pagamentos em Mercados Emergentes. In: KRUGMAN, P (org). Crises Monetárias. 1. ed. Princeton: Makron Books, 2001.

CALVO, Guillermo A. e MENDOZA, Enrique G. Rational Contagion and the Globalization of Securities Markets. National Bureau of Economic Research Working Papers. n.7153, May, 1999. Disponível em: <http://www.nber.org>.

CARDOSO E. e HELWEGE, A. A Currency Crises in the 1990: the Case of Brazil. 1999. Disponível em: http://www.imf.org.

DAMASCENO, A.O. Liberalização da Conta de Capitais e Crescimento Econômico: Evidências de Dados em Painel para a América Latina. Anais do XXXIII Encontro Nacional de Economia. Natal, 2005.

DAVIDSON, P. “Especulação cambial e moeda internacional: Tobin versus Keynes”. In: FERRARI FILHO, Fernando, FERNANDO DE PAULA, Luiz. Globalização Financeira: ensaios de macroeconomia aberta. 1.ed. Rio de Janeiro: Editora Vozes, 2004. p.654. p.335-368.

DEQUECH, David. Incerteza num sentido forte: significado e fontes. In: LIMA, G.T., Sicsú, J. e PAULA, Luiz F. (org.) Macroeconomia Moderna - Keynes e a Economia Contemporânea. Rio de Janeiro: Editora Campus, 1999.

DIAMOND, D e DYBVIG, P. "Bank Runs, Liquidity and Deposit Insurance”. Journal of Political Economy, n.91, p.410-419. 1983.

EDISON, H. J.; KLEIN, M.W., RICCI, L, SLOEK, T. Capital Account Liberalization and Economica Perfomance: Survey and Synthesis. NBER, Working Paper 9100, 2002.

EDISON, H.J., LEVINE, R., RICCI, SLOEK, T. International Financial Integration and Economic Growth, NBER, Working Paper 9164, 2002.

EICHENGREEN, B. MUSSA, Michael, DETRAGIACHE, Enrica e DELL'ARICCIA, Giovanni. Capital Account Liberalization: Theoretical and Practical Aspects. Washington, IMF, Occasional Paper $n^{\circ} 172,1998$.

EICHENGREEN, B. E JEANNE, Oliver. Crise monetária e desemprego.In: KRUGMAN, P. Crises Monetárias. 1. ed. Princeton: Makron Books, 2004. p.1-46.

FISHER, Stanley. Capital Account Liberalization and the Role of the IMF. In: PETER, B. Kene (ed.) Should the IMF Pursue Capital-Account Convertibility. Princeton University, Department of Economics, Essays in International Finance n²07, 1998.

FLEMING, J. Domestic financial policies under fixed and under floating exchange rates. Staff Papers/IMF, n. ${ }^{\circ} 2:$ 369-379, November, 1962.

FRANCO, G.H.B., NETO, D.M.P. A desregulamentação da conta de capitais: limitações macroeconômicas e regulatórias. In: Aprimorando o mercado de câmbio brasileiro, BM\&F, São PauloSP. 2004.

FRANKEL, JA, SCHMUKLER, S. and SERVÉN, L. Verifiability and the vanishing Intermediate Exchange Rate Regime, NBER Working Paper 7901. 2000.

FRANKEL, Jeffrey A. No single currency regime is right for all countries or at all times. NBER. Working Paper 7338. 1999

FRIEDMAN, M. The case for flexible exchange rates, in Essays in Positive Economics, University of Chicago Press, Chicago, p.157-203. 1953

GAROFALO FILHO, Emílio. Câmbios no Brasil: as peripécias da moeda nacional e a política cambial, 500 anos depois 1.ed. São Paulo: Bolsa de Mercadorias e Futuros (BM\&F). 2000. p.253.

GRENVILLE, S. Exchange Rate Regimes for Emerging Markets. Sydney: Reserve Bank of Australia Bulletin, November, 2000.

HART, Oliver D. e KREPS, David P. Price destabilizing speculation. Journal of Political Economy, vol. $94, \mathrm{n}^{\circ} 5$. 
JOHNSON, H. G. The case for flexible Exchange rates, 1969. Further Essays in Monetary Economics, Allen and Unwin, London, p.198-228. 1972.

KALDOR, Nicholas. Speculation and Economic Stability. Illinois: The Free Press of Glencoe, 1960.

KEYNES, J. M. “Teoria Geral do Emprego, do Juro e da Moeda”. São Paulo: Atlas [Edição Original: 1936]

KREGEL, J. Risco e implicações da globalização financeira para a autonomia de políticas nacionais. In: FERRARI FILHO, Fernando, PAULA, Luiz F. Globalização Financeira: ensaios de macroeconomia aberta. 1.ed. Rio de Janeiro: Editora Vozes, 2004. p.654. p.31-58.

KRUGMAN, P (org). Crises Monetárias. 1. ed. Princeton: Makron Books, 2001. - What happened to Asia? Cambridge: Massachusetts Institute of Technology, Janeiro, 1998 (mimeo). . “Currency Crisis”, MIT, 1997.(mimeo).

LICHA, A. L. Volatilidade de Capitais de Curto Prazo em Países Emergentes - XXVIIII Encontro Nacional de Economia, ANPEC, Campinas, 2000.

MUNDELL, R. Capital mobility and stabilization policy under fixed and flexible exchange rates. $\mathrm{Ca}$ nadian Journal of Economics and Political Science, 29: 475-485, November. 1963.

OBSTFELD, M. e ROGOFF, K. Foundations of International Macroeconômics. The MIT Press, Massachusetts Institute of Technology, Cambridge. 1996.

OBSTFELD, Maurice. Models of currency crises with self-fulfilling features. European Economic Review. 40(3/5): 1037-1047. 1996.

. The Logic of currency crises. Cashiers Économiques et Monetaires. 43:189-213. 1994.

ONO, F.H., SILVA, G.J., OREIRO, J.L. e PAULA, L.F. e Uma avaliação empírica da proposta de conversibilidade do real. In: SICSÚ, J. e FERRARI FILHO. Câmbio e Controle de Capitais: avaliando a eficiência de modelos macroeconômicos. Rio de Janeiro: Campus. 2006.

OREIRO, J.L. Autonomia de Política Econômica, Fragilidade Financeira Externa e Equilíbrio do Balanço de Pagamentos. Economia e Sociedade, 13(2): 1-22. 2004.

PAULA, L.F; OREIRO, J.L.; JONAS, G. Fluxos e Controles de Capitais no Brasil: avaliação e proposta de política. In SICSÚ, J; OREIRO, J.L.; PAULA, L.F. Agenda Brasil: políticas econômicas para o crescimento com estabilidade de preços. Barueri: Manole. 2003.

PRASAD, E e ROGOFF, K. et elli. Effects of Financial Globalization on Developing Countries: some empirical Evidence. IMF, 2003.

QUINN, D. The Correlates of Change in International Financial Regulation. American Political Science Review, vol. 91, n 3, p. 531-551, 1997.

RADELET, S. \& SACHS, J.D. The East Asian financial crisis: diagnosis, remedies, prospects. Brookings Papers on Economic Activity. n. ${ }^{\circ}$ 01, p.01-90. 1998.

. O Despontar da Crise Financeira do Leste Asiático. In: KRUGMAN, P (org). Crises Monetárias. 1. ed. Princeton: Makron Books, 2001.

RODRIK, D. Who Needs Capital-Account Convertibility? 1998. Disponível em: http://ksghome.harvard.edu/ drodrik/. Acessado em: Agosto de 2006.

RODRIK, D e VELASCO, A. Short Term Capital Flows. NBER. Working Paper n. 7364. 1999.

SCHARFSTEIN, D. e STEIN, J. "Herd Behaviour and Investment". The American Economic Review, Junho, 1993.

SOIHET, E. "Índice de Controle de Capitais: Uma Análise da Legislação e dos Determinantes do Fluxo de Cpaital no Brasil no Período 1990-2000”. Dissertação de Metrado. Rio de Janeiro: FGV/EPGE, 2002.

STIGLITZ, J. Globalization and its discontents. Penguin Books, Londres, 2002.

TOBIN, J. A Proposal for International Monetary Reform. Eastern Economic Journal, vol.4. 1978.

VELASCO, A. "Fixed Exchange Rates: credibility, flexibility and multiplicity". European Economic Review, n.40. 1996. 